Please do not remove this page

RMIT

UNIVERSITY

\title{
Nonlinear free vibration of shear deformable sandwich beam with a functionally graded porous core
}

Chen, Da; Kitipornchai, Sritawat; Yang, Jie

https://researchrepository.rmit.edu.au/esploro/outputs/9921860379701341/filesAndLinks?institution=61RMIT_INST\&index=null

Chen, D., Kitipornchai, S., \& Yang, J. (2016). Nonlinear free vibration of shear deformable sandwich beam with a functionally graded porous core. Thin-Walled Structures, 107, 39-48.

https://doi.org/10.1016/j.tws.2016.05.025

Document Version: Submitted Version

Published Version: https://doi.org/10.1016/j.tws.2016.05.025

Repository homepage: https://researchrepository.rmit.edu.au

(c) 2016 Elsevier Ltd. All rights reserved.

Downloaded On 2023/04/26 19:00:47 +1000 
Thank you for downloading this document from the RMIT Research Repository.

The RMIT Research Repository is an open access database showcasing the research outputs of RMIT University researchers.

RMIT Research Repository: http://researchbank.rmit.edu.au/

\section{Citation: \\ Chen, D, Kitipornchai, S and Yang, J 2016, 'Nonlinear free vibration of shear deformable sandwich beam with a functionally graded porous core', Thin-Walled Structures, vol. 107, pp. 39-48.}

See this record in the RMIT Research Repository at:

https://researchbank.rmit.edu.au/view/rmit:38644

Version: Submitted Version

\section{Copyright Statement:}

(c) 2016 Elsevier Ltd. All rights reserved.

Link to Published Version:

http://dx.doi.org/10.1016/j.tws.2016.05.025 


\title{
Nonlinear free vibration of shear deformable sandwich beam with a functionally graded porous core
}

\author{
Da Chen ${ }^{\text {a }}$, Sritawat Kitipornchai ${ }^{\text {a }}$, Jie Yang ${ }^{\text {b,* }}$ \\ ${ }^{a}$ School of Civil Engineering, the University of Queensland, Brisbane, St Lucia 4072, Australia \\ ${ }^{b}$ School of Engineering, RMIT University, PO Box 71, Bundoora, VIC 3083 Australia
}

\begin{abstract}
The nonlinear free vibration behavior of shear deformable sandwich porous beam is investigated in this paper within the context of Timoshenko beam theory. The proposed beam is composed of two face layers and a functionally graded porous core which contains internal pores following different porosity distributions. Two non-uniform functionally graded distributions are considered in this paper based on the equivalent beam mass, associated with a uniform distribution for purpose of comparison. The elastic moduli and mass density are assumed to vary along the thickness direction in terms of the coefficients of porosity and mass density, whose relationship is determined by employing the typical mechanical characteristics of an open-cell metal foam. The Ritz method and von Kármán type nonlinear strain-displacement relationships are applied to derive the equation system, which governs the nonlinear vibration behavior of sandwich porous beams under hinged or clamped end supports. A direct iterative algorithm is then used to solve the governing equation system to predict the linear and nonlinear frequencies which are presented by a detailed numerical study to discuss the effects of porosity coefficient, slenderness ratio, thickness ratio and to compare the varying porosity distributions and boundary conditions, providing a feasible way to improve the vibration behavior of sandwich porous beams.
\end{abstract}

\section{Keywords:}

Sandwich beam; functionally graded porous core; nonlinear free vibration; Timoshenko beam theory; Ritz method.

\section{Introduction}

Porous materials, such as metal foams, are receiving worldwide interests as advanced engineering materials in aerospace engineering, automotive industry and civil constructions

\footnotetext{
*Corresponding author. Tel.: 61-3-99256169 (J. Yang)

E-mail address: j.yang@rmit.edu.au (J. Yang)
} 
due to their excellent multi-functionality offered by low specific weight, efficient capacity of energy dissipation, reduced thermal and electrical conductivity, enhanced recyclability and machinability [1-10].

Sandwich structures with a porous core are a form of weight-efficient structures consisting of three major parts: two thin face layers that provide the in-plane and bending stiffness and a thick core sandwiched between that carries the transverse normal and shear loads as well as serves as a heat diffuser or acoustic and vibration damper due to the novel properties of porous materials. Over the past few years, the static and dynamic properties of sandwich porous beams and plates have been extensively investigated by various theoretical and experimental studies [11-26].

However, most of the studies available in open literature did not consider the possible performance improvement offered by a functionally graded (FG) porous structure which involves a non-uniform porosity distribution across the thickness. Research work to explore this effect is quite limited. Magnucki and Stasiewicz [27] obtained an explicit expression for the critical buckling load of a rectangular FG porous beam under a lengthwise compressive force. Chen et al. [28] studied the elastic buckling and static bending problems of shear deformable FG porous beams within the frame of Timoshenko beam theory, considering two different non-uniform porosity distribution patterns and four types of boundary conditions. They [29] also employed the Lagrange equation method with Ritz trial functions in the space domain and Newmark- $\beta$ method in the time domain to examine the free and forced vibrations of FG porous beams under various loading conditions.

It should be noted that the above-mentioned studies are all about the linear analysis of FG porous structures of which the nonlinear behavior is also crucial owing to their widespread use in the practical applications allowing large deformations. Magnucka-Blandzi and Magnucki [30] performed the effective design of optimal dimensionless parameters of a simply supported sandwich beam with an FG metal foam core based on a nonlinear hypothesis of deformation and the theorem of minimum total potential energy. MagnuckaBlandzi [31] proposed the mathematical modelling of a simply supported rectangular sandwich porous plate with differential equations formulated by using the principle of stationarity of the total potential energy. Grygorowicz et al. [32] presented analytical and numerical studies of elastic buckling of a sandwich beam with FG porous core under a broken line hypothesis and a nonlinear hypothesis to define the displacement fields. Mojahedin et al. [33] used the higher order shear deformation plate theory and nonlinear strain-displacement relations to derive the closed form solution for the critical buckling load of a radically loaded circular plate made of FG porous materials saturated with fluid, and compared the results with the outcome of classical and first order plate theories.

The nonlinear vibration behavior is another important property that needs to be fully understood, especially for structures that are often subjected to strong dynamic loadings in engineering applications. Kitipornchai et al. [34] applied a semi-analytical method to the nonlinear vibration analysis of imperfect shear deformable laminated rectangular plates with Reddy's higher-order shear deformation plate theory, and obtained the vibration frequencies under different boundary conditions. Rafiee et al. [35] analysed large amplitude free vibration 
of FG carbon nanotube reinforced composite beams with surface-bonded piezoelectric layers under a temperature change and an applied voltage according to the Euler-Bernoulli beam theory, von Kármán geometric nonlinearity and the physical neutral surface concept. Belouettar et al. [36] developed a simplified and consistent methodology to actively control the nonlinear vibration of a piezoelectric-elastic-piezoelectric beams at small and large amplitudes using harmonic balance method. However, no previous work has been done for the nonlinear vibration of FG porous structures.

The present study gives a nonlinear free vibration analysis of shear deformable sandwich porous beams. The effects of transverse shear deformation and rotary inertia are taken into account based on Timoshenko beam theory. The proposed porous core is made of open-cell metal foam of which the mechanical property is used to derive the relationship between coefficients of porosity and mass density. Ritz method in combination with a direct iterative algorithm is employed to obtain linear fundamental and nonlinear vibration frequencies of sandwich porous beams. Two non-uniform FG porosity distributions and a uniform distribution are considered and the performances of the beam with different porosity distributions are compared. Comprehensive numerical results are provided to examine the effects of porosity coefficient, slenderness ratio, and thickness ratio as well.

\section{Porosity distributions}

A sandwich porous beam of length $L$, width $b$ and its $x-z$ Cartesian coordinate system are shown in Fig. 1. The total beam thickness is $h_{t}=h_{c}+2 h_{f}$, where $h_{c}$ denotes the core thickness and $h_{f}$ is the thickness of face layers that are assumed to be perfectly bonded to the core material. The internal pores in the core follow either non-uniform FG porosity distribution or uniform distribution as shown in Fig. 2, resulting in position-dependent variations of Young modulus $E(z)$, shear modulus $G(z)$ and mass density $\rho(z)$, described by Eq. (1) for distribution 1, Eq. (2) for distribution 2 and Eq. (3) for uniform distribution [28, 29].

It is seen from Fig. 2 that porosity distribution 1 is symmetrical about $x$-axis with elastic moduli and mass density decreasing from top/bottom surfaces to the mid-plane while porosity distribution 2 is asymmetrical with continuous recession of material properties along thickness direction. 


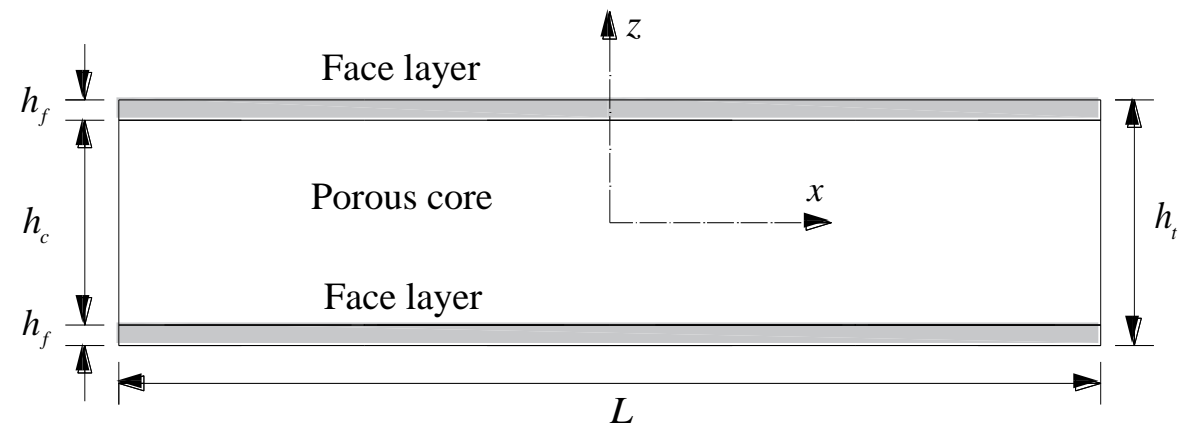

Fig. 1. A sandwich porous beam.
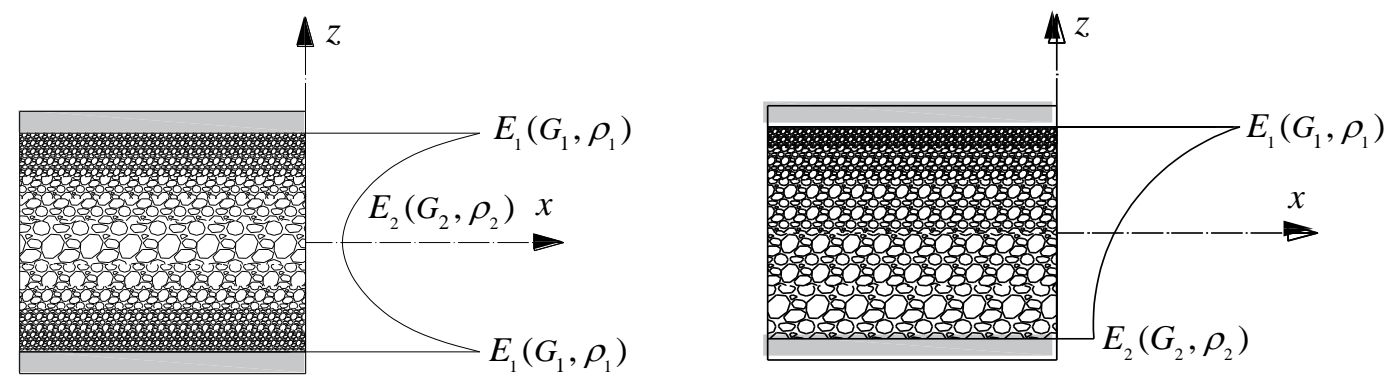

(a) Non-uniform porosity distribution 1

(b) Non-uniform porosity distribution 2

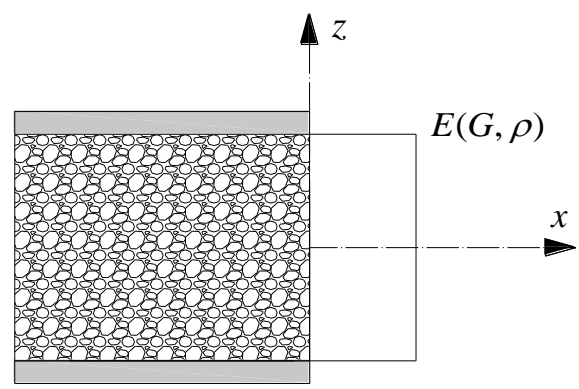

(c) Uniform porosity distribution

Fig. 2. Porous cores with different porosity distributions.

$$
\begin{aligned}
& \left\{\begin{array}{l}
E(z)=E_{1}\left[1-e_{0} \cos (\pi \xi)\right] \\
G(z)=G_{1}\left[1-e_{0} \cos (\pi \xi)\right] \\
\rho(z)=\rho_{1}\left[1-e_{m} \cos (\pi \xi)\right]
\end{array}\right. \\
& \left\{\begin{array}{l}
E(z)=E_{1}\left[1-e_{0} \cos (\pi \xi / 2+\pi / 4)\right] \\
G(z)=G_{1}\left[1-e_{0} \cos (\pi \xi / 2+\pi / 4)\right] \\
\rho(z)=\rho_{1}\left[1-e_{m} \cos (\pi \xi / 2+\pi / 4)\right]
\end{array}\right.
\end{aligned}
$$




$$
\left\{\begin{array}{l}
E(z)=E_{1}\left(1-e_{0} \alpha\right) \\
G(z)=G_{1}\left(1-e_{0} \alpha\right) \\
\rho(z)=\rho_{1} \sqrt{1-e_{0} \alpha}
\end{array}\right.
$$

where $\xi=z / h_{c}\left(-h_{c} / 2 \leq z \leq h_{c} / 2\right), E_{1}$ and $E_{2}$ denote the maximum and minimum values of Young's modulus for non-uniform porosity distributions, respectively, $G_{i}$ and $\rho_{i}(i=1,2)$ are the corresponding extremum values of shear modulus and mass density, $e_{0}$ and $e_{m}$ represent the coefficients of porosity and mass density and can be expressed as

$$
\begin{aligned}
& e_{0}=1-\frac{E_{2}}{E_{1}}=1-\frac{G_{2}}{G_{1}}, 0 \leq e_{0}<1 \\
& e_{\mathrm{m}}=1-\frac{\rho_{2}}{\rho_{1}}, 0 \leq e_{\mathrm{m}}<1
\end{aligned}
$$

$e_{0}$ is used as the principal variable to describe the porosity and $e_{\mathrm{m}}$ is determined by their relationship which is derived according to the typical mechanical characteristic of an opencell metal foam. A larger value of $e_{0}$ corresponds to lower elastic moduli and mass density due to the increased size and density of internal pores. It should be noted that $e_{0}=e_{\mathrm{m}}=0$ indicates a special case where no pore exists in the core whereas $e_{0}=e_{\mathrm{m}}=1$ cannot be achieved since in this case, all material property values are reduced to zero.

The typical mechanical property of an open-cell metal foam [1, 28, 29, 37] expressed in Eq. (6) is used to determine the relationship between $e_{0}$ and $e_{m}$ in Eq. (7).

$$
\begin{aligned}
& \frac{E_{2}}{E_{1}}=\left(\frac{\rho_{2}}{\rho_{1}}\right)^{2} \\
& e_{\mathrm{m}}=1-\sqrt{1-e_{0}}
\end{aligned}
$$

With uniform porosity distribution, the material properties of the core are constant along the beam thickness. On the basis of the equivalent mass of sandwich porous beams, the coefficient $\alpha$ in Eq. (3) is obtained as

$$
\alpha=\frac{1}{e_{0}}-\frac{1}{e_{0}}\left(\frac{2}{\pi} \sqrt{1-e_{0}}-\frac{2}{\pi}+1\right)^{2}
$$

\section{Theoretical formulations}

\subsection{Total energy of sandwich porous beams}


Let $u_{x}$ and $w_{z}$ be the displacements parallel to $x$ - and $z$-axes, $u_{0}$ and $w_{0}$ stand for the displacements of a certain point on the mid-plane, $\phi_{x}$ be the mid-plane rotation of transverse normal, and $t$ denotes the time. According to Timoshenko beam theory, the displacement fields $\left(u_{x}, w_{x}\right)$ that account for the effects of transverse shear strains are of the form as

$\left\{\begin{array}{l}u_{x}(x, z, t)=u_{0}(x, t)+z \phi_{x}(x, t) \\ w_{z}(x, z, t)=w_{0}(x, t)\end{array}\right.$

The geometrically nonlinear normal strain $\varepsilon_{x x}$ and transverse strain $\gamma_{x z}$ are associated with the displacements via von Kármán type nonlinear strain-displacement relationship as

$\left\{\begin{array}{l}\varepsilon_{x x}=\frac{\partial u_{0}}{\partial x}+\frac{1}{2}\left(\frac{\partial w_{0}}{\partial x}\right)^{2}+z \frac{\partial \phi_{x}}{\partial x} \\ \gamma_{x z}=\frac{\partial w_{0}}{\partial x}+\phi_{x}\end{array}\right.$

The linear elastic strain-stress constitutive law is given as

$\left\{\begin{array}{l}\sigma_{x x}=Q_{11}(z) \varepsilon_{x x} \\ \sigma_{x z}=Q_{55}(z) \gamma_{x z}\end{array}\right.$

and the related elastic constants are

$$
\left\{\begin{array}{l}
Q_{11}(z)=\frac{E(z)}{1-v_{c}^{2}} \\
Q_{55}(z)=G(z)=\frac{E(z)}{2\left(1+v_{c}\right)}
\end{array}\right.
$$

where $v_{c}$ denotes Poisson's ratio of the porous core. It is worth noting that the value of $v_{c}$ keeps constant along the beam thickness [1], since Poisson's ratio is the negative ratio of the lateral to the axial strain and both of them are proportional to the bending deflection per cell length for cellular structures, thus their ratio is a constant [2]. The strain energy $U$ of the beam at an arbitrary instant is calculated by

$U=\frac{1}{2} \int_{0}^{L} \int_{-h_{t} / 2}^{h_{t} / 2}\left(\sigma_{x x} \varepsilon_{x x}+\sigma_{x z} \gamma_{x z}\right) \mathrm{d} z \mathrm{~d} x$

which can be expressed in terms of $u_{0}, w_{0}, \phi_{x}$ as below by making use of Eqs. (10)-(12)

$U=\frac{1}{2} \int_{0}^{L}\left\{A_{11}\left[\frac{\partial u_{0}}{\partial x}+\frac{1}{2}\left(\frac{\partial w_{0}}{\partial x}\right)^{2}\right]^{2}+2 B_{11}\left[\frac{\partial \phi_{x}}{\partial x} \frac{\partial u_{0}}{\partial x}+\frac{1}{2} \frac{\partial \phi_{x}}{\partial x}\left(\frac{\partial w_{0}}{\partial x}\right)^{2}\right]+D_{11}\left(\frac{\partial \phi_{x}}{\partial x}\right)^{2}+A_{55}\left(\phi_{x}+\frac{\partial w_{0}}{\partial x}\right)^{2}\right\} d x$ 
The stiffness components $A_{11}, B_{11}, D_{11}$ and $A_{55}$ of the sandwich beam include the contribution from both the porous core and face layers and are given by

$$
\left\{\begin{array}{l}
\left\{A_{11}, B_{11}, D_{11}\right\}=\int_{h_{c} / 2}^{h_{c} / 2+h_{f}} \frac{E_{f}}{1-v_{f}^{2}}\left\{1, z, z^{2}\right\} \mathrm{d} z+\int_{-h_{c} / 2}^{h_{c} / 2} Q_{11}(z)\left\{1, z, z^{2}\right\} \mathrm{d} z+\int_{-h_{c} / 2-h_{f}}^{-h_{c} / 2} \frac{E_{f}}{1-v_{f}^{2}}\left\{1, z, z^{2}\right\} \mathrm{d} z \\
A_{55}=\int_{h_{c} / 2}^{h_{c} / 2+h_{f}} k G_{f} \mathrm{~d} z+\int_{-h_{c} / 2}^{h_{c} / 2} k Q_{55}(z) \mathrm{d} z+\int_{-h_{c} / 2-h_{f}}^{-h_{c} / 2} k G_{f} \mathrm{~d} z
\end{array}\right.
$$

where $E_{f}, v_{f}$ and $G_{f}\left(G_{f}=E_{f} / 2\left(1+v_{f}\right)\right)$ are Young's modulus, Poisson's ratio and shear modulus of the face layers. The shear correction factor $k=5 / 6$. The kinetic energy $T$ of the sandwich beam can be written as

$T=\frac{1}{2} \int_{0}^{L}\left\{I_{0}\left[\left(\frac{\partial u_{0}}{\partial t}\right)^{2}+\left(\frac{\partial w_{0}}{\partial t}\right)^{2}\right]+2 I_{1} \frac{\partial u_{0}}{\partial t} \frac{\partial \phi_{x}}{\partial t}+I_{2}\left(\frac{\partial \phi_{x}}{\partial t}\right)^{2}\right\} d x$

in which the inertia terms $I_{0}, I_{1}$ and $I_{2}$ are also due to the porous core and face layers with mass density $\rho_{f}$

$$
\left\{I_{0}, I_{1}, I_{2}\right\}=\int_{h_{c} / 2}^{h_{c} / 2+h_{f}} \rho_{f}\left\{1, z, z^{2}\right\} \mathrm{d} z+\int_{-h_{c} / 2}^{h_{c} / 2} \rho(z)\left\{1, z, z^{2}\right\} \mathrm{d} z+\int_{-h_{c} / 2-h_{f}}^{-h_{c} / 2} \rho_{f}\left\{1, z, z^{2}\right\} \mathrm{d} z
$$

Introducing the following dimensionless quantities to facilitate the theoretical formulations hereafter

$$
\begin{aligned}
& \left\{u^{\prime}, w^{\prime}\right\}=\frac{\left\{u_{0}, w_{0}\right\}}{h_{t}}, \phi^{\prime}=\phi_{x}, \zeta=\frac{x}{L},\left\{a_{11}, b_{11}, d_{11}, a_{55}\right\}=\left\{\frac{A_{11}}{A^{*}}, \frac{B_{11}}{A^{*} h_{t}}, \frac{D_{11}}{A^{*} h_{t}^{2}}, \frac{A_{55}}{A^{*}}\right\}, \eta=\frac{L}{h_{t}}, \\
& \left\{l_{0}, l_{1}, l_{2}\right\}=\left\{\frac{I_{0}}{I^{*}}, \frac{I_{1}}{I^{*} h_{t}}, \frac{I_{2}}{I^{*} h_{t}^{2}}\right\}, \tau=t \sqrt{\frac{A^{*}}{I^{*} L^{2}}}, \omega=\Omega L \sqrt{\frac{I^{*}}{A^{*}}}
\end{aligned}
$$

where $A^{*}$ and $I^{*}$ denote the values of $A_{11}$ and $I_{0}$ of a sandwich beam with a solid core without pores, $\omega$ stands for the dimensionless form of natural frequency $\Omega$.

For harmonic vibration, the dynamic displacements of the sandwich beam take the form of

$\left\{u^{\prime}(\zeta, \tau), w^{\prime}(\zeta, \tau), \phi^{\prime}(\zeta, \tau)\right\}=\{u(\zeta), w(\zeta), \phi(\zeta)\} e^{i \omega \tau}$

where $i=\sqrt{-1}$. Substituting Eqs. (18)-(19) into Eqs. (14) and (16) leads to the following dimensionless forms of strain energy and kinetic energy 


$$
\left\{\begin{array}{l}
\bar{U}=\frac{U}{\left(A^{*} h_{t}^{2} / L\right) e^{2 i \omega \tau}}=\bar{U}_{\text {Linear }}+\bar{U}_{\text {Nonlinear }} \\
\bar{U}_{\text {Linear }}=\frac{1}{2} \int_{0}^{1}\left[a_{11}\left(\frac{\partial u}{\partial \zeta}\right)^{2}+2 b_{11} \frac{\partial u}{\partial \zeta} \frac{\partial \phi}{\partial \zeta}+d_{11}\left(\frac{\partial \phi}{\partial \zeta}\right)^{2}+a_{55}\left(\frac{\partial w}{\partial \zeta}+\eta \phi\right)^{2}\right] \mathrm{d} \zeta \\
\bar{U}_{\text {Nonlinear }}=\frac{1}{2} \int_{0}^{1}\left[\frac{a_{11}}{\eta} \frac{\partial u}{\partial \zeta}\left(\frac{\partial w}{\partial \zeta}\right)^{2}+\frac{a_{11}}{4 \eta^{2}}\left(\frac{\partial w}{\partial \zeta}\right)^{4}+\frac{b_{11}}{\eta} \frac{\partial \phi}{\partial \zeta}\left(\frac{\partial w}{\partial \zeta}\right)^{2}\right] \mathrm{d} \zeta \\
\bar{T}=\frac{T}{\left(A^{*} h_{t}^{2} / L\right) e^{2 i \omega \tau}}=-\frac{1}{2} \omega^{2} \int_{0}^{1}\left\{l_{0}\left(u^{2}+w^{2}\right)+2 l_{1} u \phi+t_{2} \phi^{2}\right\} d \zeta
\end{array}\right.
$$

The dimensionless total energy of the sandwich porous beam can then be expressed as

$$
\Pi=\bar{T}+\bar{U}
$$

\subsection{Ritz method and iterative algorithm}

The equation system governing the linear and nonlinear free vibrations is derived for sandwich beams with hinged $(\mathrm{H})$ or clamped $(\mathrm{C})$ end supports by using Ritz method. The dimensionless displacements $u, w$ and $\phi$ that satisfy the geometric conditions of the beam are expanded in algebraic polynomials as

$$
\begin{aligned}
& u(\zeta)=\sum_{j=1}^{N} R_{1 j} \zeta^{j}(1-\zeta) \\
& w(\zeta)=\sum_{j=1}^{N} R_{2 j} \zeta^{j}(1-\zeta) \\
& \phi(\zeta)= \begin{cases}\sum_{j=1}^{N} R_{3 j} \zeta^{j-1}, & \text { for hinged-hinged (H-H) beam } \\
\sum_{j=1}^{N} R_{3 j} \zeta^{j}(1-\zeta), & \text { for clamped-clamped (C-C) beam } \\
\sum_{j=1}^{N} R_{3 j} \zeta^{j}, & \text { for clamped-hinged (C-H) beam }\end{cases}
\end{aligned}
$$

where $N$ denotes the total number of polynomial terms, $R_{1 j}, R_{2 j}$ and $R_{3 j}(j=1,2, \cdots, N)$ are the undetermined coefficients. Substituting the above dimensionless displacements into Eq. (22) and employing the standard Ritz procedure to minimize the total energy give

$$
\frac{\partial \Pi}{\partial R_{i j}}=0 \quad(i=1,2,3 ; j=1,2, \cdots, N)
$$


which leads to the governing equation system in matrix form as

$\left(\mathbf{K}_{\text {Linear }}+\mathbf{K}_{\text {Nonlinear }}-\omega^{2} \mathbf{M}\right) \mathbf{d}=0$

in which $\mathbf{K}_{\text {Linear }}$ and $\mathbf{K}_{\text {Nonlinear }}$ are the linear and nonlinear symmetric stiffness matrices $(3 N \times 3 N)$, respectively, $\mathbf{M}$ stands for the symmetric mass matrix $(3 N \times 3 N)$, $\mathbf{d}$ is the vector consisting of undetermined coefficients $\left(\mathbf{d}=\left\{\left\{R_{1 j}\right\}^{\mathrm{T}}\left\{R_{2 j}\right\}^{\mathrm{T}}\left\{R_{3 j}\right\}^{\mathrm{T}}\right\}^{\mathrm{T}}\right)$.

A direct iterative algorithm is applied to solve Eq. (27) to obtain the linear and nonlinear frequencies of the sandwich porous beam. It should be noted that beams with symmetric porosity distribution, i.e., non-uniform porosity distribution 1 and uniform porosity distribution, vibrate with same amplitudes at positive and negative cycles due to the equal and opposite roots produced from the energy balance equation ( $U-T=0$ ) [38]. By following the process from steps $\mathrm{A} 1$ to $\mathrm{A} 2$, their nonlinear frequencies can be calculated from positive deflection cycles by continuously updating the eigenvector from Eq. (27) to make the associated eigenvalue approach to the given value.

A1. Before proceeding to the nonlinear analysis, the dimensionless linear fundamental natural frequency $\omega_{l}$ of the beam needs to be solved from Eq. (27) by neglecting the nonlinear matrix $\mathbf{K}_{\text {Nonlinear }}$. The associated eigenvector is used to calculate the linear beam deflection.

A2. For a given maximum deflection $\left(w_{\max }=w(0.5)\right.$ for $\mathrm{H}-\mathrm{H}$ and $\mathrm{C}-\mathrm{C}$ beams, $w_{\max }=w(0.57)$ for $\mathrm{C}-\mathrm{H}$ beam), scaling up the calculated eigenvector based on the given and calculated maximum deflections then substituting it into $\mathbf{K}_{\text {Nonlinear }}$ to update the governing equation system, which, in turn, yields a new eigenvalue and eigenvector which are nonlinear. This iteration progress is repeated until the obtained eigenvalues from two consecutive iterations are close enough (relative error $\leq 0.1 \%$ ) to obtain the nonlinear frequency $\omega_{n l}$.

For beams with porosity distribution 2 which is asymmetric, the existence of bendingextension coupling effect within the beam leads to different vibration amplitudes at positive and negative half cycles. In this case, steps B1 to B3 need to be followed to calculate their nonlinear frequencies based on the identical energy consumed in both positive and negative deflection half cycles.

B1. Based on the calculations from A1 to A2, the maximum potential energy $U_{\max }^{+}$of the sandwich beam during positive half cycle is computed using the final eigenvector given in A2 which indicates the largest positive deformation of the beam under free vibration.

B2. Same calculation procedures from A1 to B1 are conducted repeatedly to determine the nonlinear frequency at negative half cycle which produces the identical maximum potential energy $U_{\max }^{-}$as that at positive half cycle $\left(\left|U_{\max }^{-}-U_{\max }^{+}\right| / U_{\max }^{+} \leq 0.1 \%\right)$. 
B3. The nonlinear frequencies $\omega^{+}$and $\omega^{-}$at positive and negative half cycles are combined to obtain the whole cycle frequency $\omega_{n l}$ as

$$
\omega_{n l}=\frac{2 \omega^{+} \omega^{-}}{\omega^{+}+\omega^{-}}
$$

\section{Numerical results}

\subsection{Validation analysis}

As no published results for the sandwich porous beams under current consideration are available in open literature, three examples concerning the linear free vibration of sandwich beams, nonlinear vibration of isotropic beams and nonlinear vibration of FG beams are used to validate the present analysis through direct comparisons between our results and the existing ones.

Table 1 considers the linear free vibration of sandwich beams with a homogeneous core and composite face layers reinforced by functionally graded and uniformly distributed carbon nanotubes (CNTs), represented by FG and UD, respectively. The CNT distribution determines the material properties of composite face layers by

$$
\left\{\begin{array}{l}
E_{11}=\eta_{1} V_{c n t} E_{11}^{c n t}+V_{m} E^{m} \\
\eta_{2} / E_{22}=V_{c n t} / E_{22}^{c n t}+V_{m} / E^{m} \\
\eta_{3} / G_{12}=V_{c n t} / G_{12}^{c n t}+V_{m} / G^{m}
\end{array}\right.
$$

where $E_{11}, E_{22}$ and $G_{12}$ are Young's moduli and shear modulus of the face layers. The material constants are $E_{11}^{c n t}=5.6466 \mathrm{TPa}, E_{22}^{c n t}=7.08 \mathrm{TPa}$ and $G_{12}^{c n t}=1.9445 \mathrm{TPa}$ for CNTs, $E^{m}=2.5 \mathrm{GPa}$ and $G^{m}=E^{m} / 2\left(1+v^{m}\right)$ for the matrix, $\eta_{i}(i=1,2,3)$ are CNT efficiency parameters, $V_{c n t}$ and $V_{m}=1-V_{c n t}$ are the volume fractions of CNTs and matrix materials, respectively. It is assumed that $V_{c n t}$ varies linearly along the thickness direction and is given as

$$
\begin{cases}V_{c n t}=\frac{-\left(2 z+h_{c}\right)}{h_{f}} V_{c n t}^{*} & \text { for top surface } \\ V_{c n t}=\frac{\left(2 z-h_{c}\right)}{h_{f}} V_{c n t}^{*} & \text { for bottom surface }\end{cases}
$$

where $V_{c n t}^{*}=0.12$, and the associated CNT efficiency parameters $\eta_{1}=0.137, \eta_{2}=1.022$ and $\eta_{3}=0.715$. In a special case where CNTs is uniformly distributed (UD), $V_{c n t}$ is constant 
across the thickness, thus $V_{c n t}=V_{c n t}^{*}$. Poisson's ratio and mass density of the face layers can be calculated by

$v=V_{c n t} v^{c n t}+V_{m} v^{m}$

$\rho=V_{c n t} \rho^{c n t}+V_{m} \rho^{m}$

in which $v^{c n t}=0.175$ and $v^{m}=0.3\left(\rho^{c n t}=1400 \mathrm{~kg} / \mathrm{m}^{3}, \rho^{m}=1190 \mathrm{~kg} / \mathrm{m}^{3}\right)$ are Poisson's ratios (mass densities) of CNTs and matrix materials, respectively. The homogeneous core is made of Titanium alloy (Ti-6Al-4V) with $E_{c}=113.8 \mathrm{Gpa}, \rho_{c}=4430 \mathrm{~kg} / \mathrm{m}^{3}$ and $v_{c}=0.342$.

\section{Table 1}

Dimensionless first three linear natural frequencies of sandwich beams with composite face layers $\left(V_{c n t}^{*}=0.12, L / h=20, h_{c} / h_{f}=8\right)$.

\begin{tabular}{|c|c|c|c|c|c|c|c|c|}
\hline $\begin{array}{c}\text { Mode } \\
\text { no. }\end{array}$ & $\begin{array}{l}\text { Face } \\
\text { sheet }\end{array}$ & $\begin{array}{l}\text { Present } \\
N=2\end{array}$ & $N=4$ & $N=6$ & $N=8$ & $N=10$ & $N=12$ & $\begin{array}{c}\text { Wu et al } \\
\text { [39] }\end{array}$ \\
\hline \multicolumn{9}{|c|}{ H-H beam } \\
\hline \multirow{2}{*}{1} & FG & 0.1612 & 0.1454 & 0.1453 & 0.1453 & 0.1453 & 0.1453 & 0.1453 \\
\hline & UD & 0.1589 & 0.1433 & 0.1432 & 0.1432 & 0.1432 & 0.1432 & 0.1432 \\
\hline \multirow{2}{*}{2} & $\mathrm{FG}$ & 3.2903 & 0.7216 & 0.5753 & 0.5730 & 0.5730 & 0.5730 & 0.5730 \\
\hline & UD & 3.2902 & 0.7117 & 0.5673 & 0.5650 & 0.5650 & 0.5650 & 0.5650 \\
\hline \multirow{2}{*}{3} & FG & 3.3298 & 1.8122 & 1.2800 & 1.2602 & 1.2599 & 1.2599 & 1.2599 \\
\hline & UD & 3.3434 & 1.7891 & 1.2627 & 1.2432 & 1.2429 & 1.2429 & 1.2429 \\
\hline \multicolumn{9}{|c|}{ C-C beam } \\
\hline \multirow{2}{*}{1} & $\mathrm{FG}$ & 0.9136 & 0.3249 & 0.3240 & 0.3240 & 0.3240 & 0.3240 & 0.3240 \\
\hline & UD & 0.9126 & 0.3204 & 0.3195 & 0.3195 & 0.3195 & 0.3195 & 0.3195 \\
\hline \multirow{2}{*}{2} & $\mathrm{FG}$ & 3.0045 & 0.8861 & 0.8706 & 0.8704 & 0.8704 & 0.8704 & 0.8704 \\
\hline & UD & 3.0044 & 0.8744 & 0.8590 & 0.8588 & 0.8588 & 0.8588 & 0.8588 \\
\hline \multirow{2}{*}{3} & $\mathrm{FG}$ & 3.3298 & 3.3081 & 1.7075 & 1.6534 & 1.6520 & 1.6520 & 1.6520 \\
\hline & UD & 3.3434 & 3.3215 & 1.6867 & 1.6326 & 1.6313 & 1.6313 & 1.6313 \\
\hline
\end{tabular}

As can be observed, the dimensionless first three natural frequencies converge to exactly the same results by $\mathrm{Wu}$ et al. [39] based on Timoshenko beam theory and differential quadrature method when $N \geq 10$.

Table 2 compares the nonlinear frequency ratio $\omega_{n l} / \omega_{l}$ of an isotropic beam with those by Marur and Prathap [40] using finite element method and Variationally Correct model. The material parameters are: Young's modulus $E=0.3 \times 10^{8} \mathrm{psi}$, shear modulus $G=0.1154 \times 10^{8}$ psi, shear correction factor $K=5 / 6$, Poisson's ratio $v=0.3$, mass density $\rho=0.1433 \times 10^{-3}$ $\mathrm{ib}-\sec ^{2} / \mathrm{in}^{4}$. Excellent agreement can be obtained. 


\section{Table 2}

Nonlinear frequency ratio $\omega_{n l} / \omega_{l}$ of an isotropic beam $(L / h=100)$.

\begin{tabular}{ccc}
\hline$W g / \theta^{*}$ & Present & Marur and Prathap [40] \\
\hline H-H beam & & \\
1 & 1.1183 & 1.1180 \\
2 & 1.4142 & 1.4135 \\
3 & 1.8033 & 1.8027 \\
C-C beam & & 1.0283 \\
1 & 1.0295 & 1.1105 \\
2 & 1.1130 & 1.2336 \\
3 & 1.2377 & 1.0582 \\
C-H beam & & 1.2150 \\
1 & 1.0596 & 1.4368 \\
2 & 1.2175 & \\
3 & 1.4402 &
\end{tabular}

Table 3 gives the nonlinear frequency ratio $\omega_{n l} / \omega_{l}$ of functionally graded carbon nanotube reinforced composite (FG-CNTRC) and uniformly distributed carbon nanotube reinforced composite (UD-CNTRC) beams with following material parameters: $E_{11}^{c n t}=600$ Gpa, $E_{22}^{c n t}=10 \mathrm{Gpa}, G_{12}^{c n t}=17.2 \mathrm{Gpa}, E^{m}=2.5 \mathrm{Gpa}, v^{c n t}=0.19, v^{m}=0.3, \rho^{c n t}=1400$ $\mathrm{kg} / \mathrm{m}^{3}, \rho^{m}=1190 \mathrm{~kg} / \mathrm{m}^{3}, V_{c n t}^{*}=0.12, \eta_{1}=1.2833, \eta_{2}=\eta_{3}=1.0556$. Our results agree well with the solutions presented by Ke et al. [41].

Table 3

Nonlinear frequency ratio $\omega_{n l} / \omega_{l}$ of FG- and UD-CNTRC beams $\left(V_{c n t}^{*}=0.12, L / h=10\right)$.

\begin{tabular}{ccccc}
\hline \multirow{2}{*}{$w_{\max }$} & \multicolumn{2}{c}{ FG-CNTRC } & \multicolumn{2}{c}{ UD-CNTRC } \\
& Present & Ke et al. [41] & Present & Ke et al. [41] \\
\hline H-H beam & & & & \\
0.1 & 1.0061 & 1.0061 & 1.0280 & 1.0278 \\
0.2 & 1.0318 & 1.0320 & 1.1076 & 1.1070 \\
0.3 & 1.0890 & 1.0873 & 1.2282 & 1.2278 \\
C-C beam & & & & \\
0.1 & 1.0166 & 1.0165 & 1.0156 & 1.0154 \\
0.2 & 1.0651 & 1.0646 & 1.0608 & 1.0605 \\
0.3 & 1.1420 & 1.1405 & 1.1326 & 1.1318 \\
C-H beam & & & & \\
0.1 & 1.0157 & 1.0160 & 1.0209 & 1.0207 \\
0.2 & 1.0615 & 1.0621 & 1.0811 & 1.0805 \\
0.3 & 1.1362 & 1.1396 & 1.1748 & 1.1735 \\
\hline
\end{tabular}




\subsection{Effects of porosity coefficient}

In what follows, parametric studies are undertaken to investigate the effects of porosity coefficient, slenderness ratio and thickness ratio on the nonlinear vibration characteristics of sandwich porous beams which are stacked as steel/steel foam/steel with the following material constants

$E_{1}=E_{f}=200 \mathrm{GPa}, \rho_{1}=\rho_{f}=7850 \mathrm{~kg} / \mathrm{m}^{3}, v_{c}=v_{f}=1 / 3, h_{t}=0.1 \mathrm{~m}$.

Figs. 3-5 illustrate the effects of porosity coefficient $e_{0}$ on the nonlinear frequency ratio $\omega_{n l} / \omega_{l}$ of the sandwich beam with different porosity distributions in the porous core. It is found that an increase in the vibration amplitude leads to a larger value of nonlinear frequency ratio, i.e. a higher nonlinear frequency, which is a typical hardening behavior [38, $41,42]$. Increasing porosity coefficient results in a lower nonlinear frequency ratio as the beam stiffness is weakened by increased size and density of the internal pores. For beams with non-uniform porosity distribution 1 and uniform porosity distribution which are symmetrical, the nonlinear frequency ratio versus vibration amplitude curve is also symmetrical, in other words, the curve is independent of the sign of vibration amplitudes, as displayed in Fig. 3 and Fig. 5 in which only the results for H-H beams are given due to the fact that $\mathrm{H}-\mathrm{H}, \mathrm{C}-\mathrm{C}$ and $\mathrm{C}-\mathrm{H}$ beams exhibit quite similar behaviour hence the results for $\mathrm{C}-\mathrm{C}$ and $\mathrm{C}-\mathrm{H}$ beams are omitted herein for brevity. For sandwich beams with non-uniform porosity distribution 2 which is asymmetrical, the curves for $\mathrm{H}-\mathrm{H}$ and $\mathrm{C}-\mathrm{H}$ beams are also asymmetrical since the equal and opposite roots cannot be produced by energy balance equation in the presence of bending-stretching coupling effect, as stated before. This effect becomes more pronounced at a larger thickness ratio $h_{c} / h_{f}$ which corresponds to a beam with thinner face layers and a thicker core. Meanwhile, the curves for C-C beams with asymmetrical porosity distribution 2 are still symmetric because the bending-stretching coupling effect is completely counter-balanced by the restoring bending moment produced at the clamped ends of the beam. 




Fig. 3. Nonlinear frequency ratio versus vibration amplitude curves for $\mathrm{H}-\mathrm{H}$ sandwich porous beams with non-uniform porosity distribution 1 : effect of porosity coefficient.

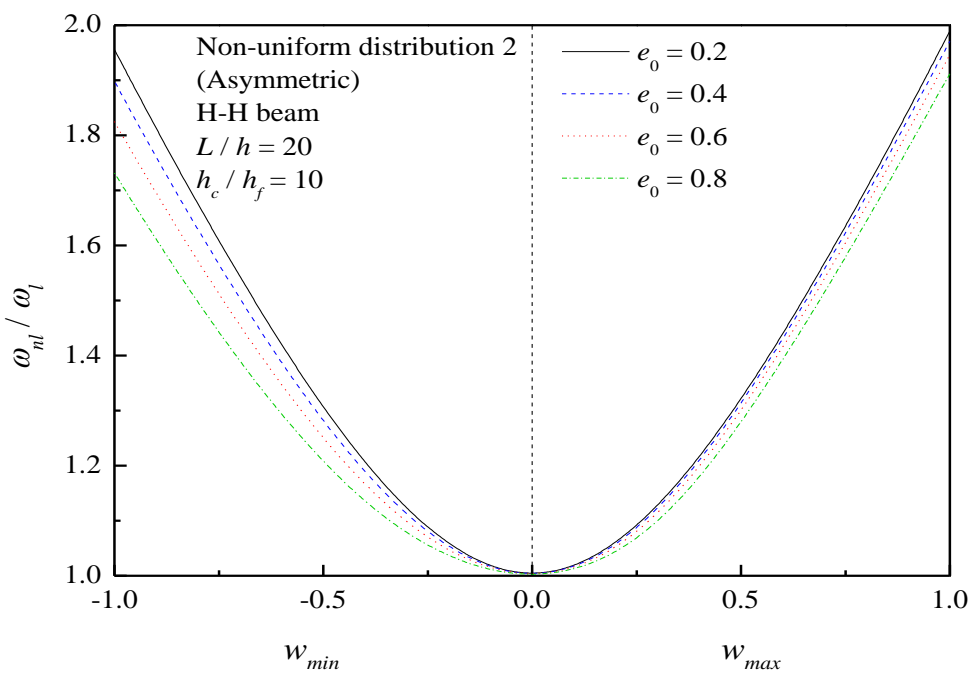

(a) H-H beam

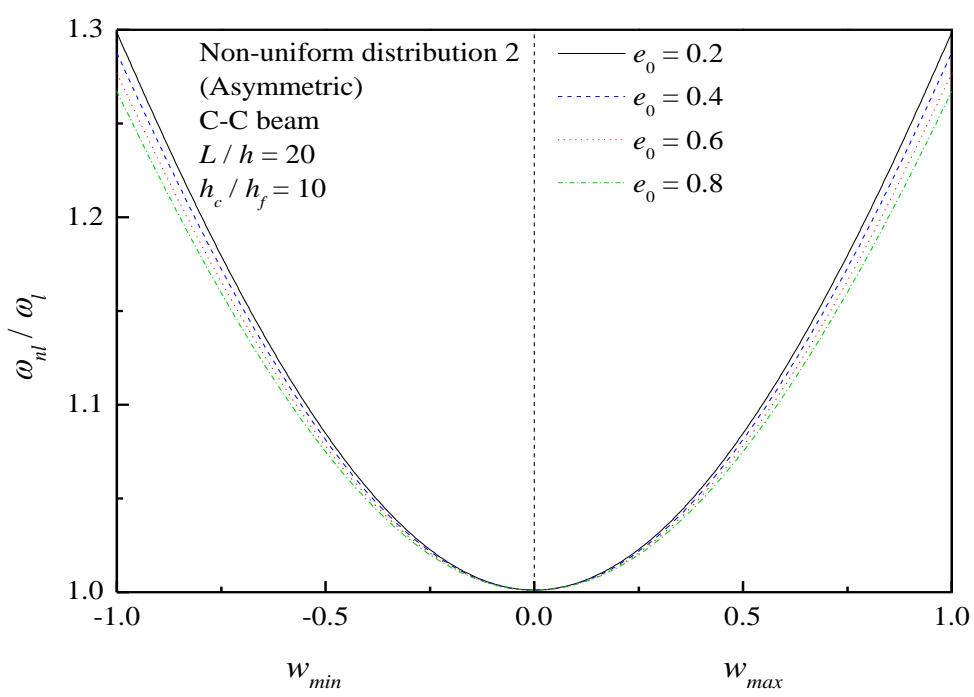

(b) C-C beam 


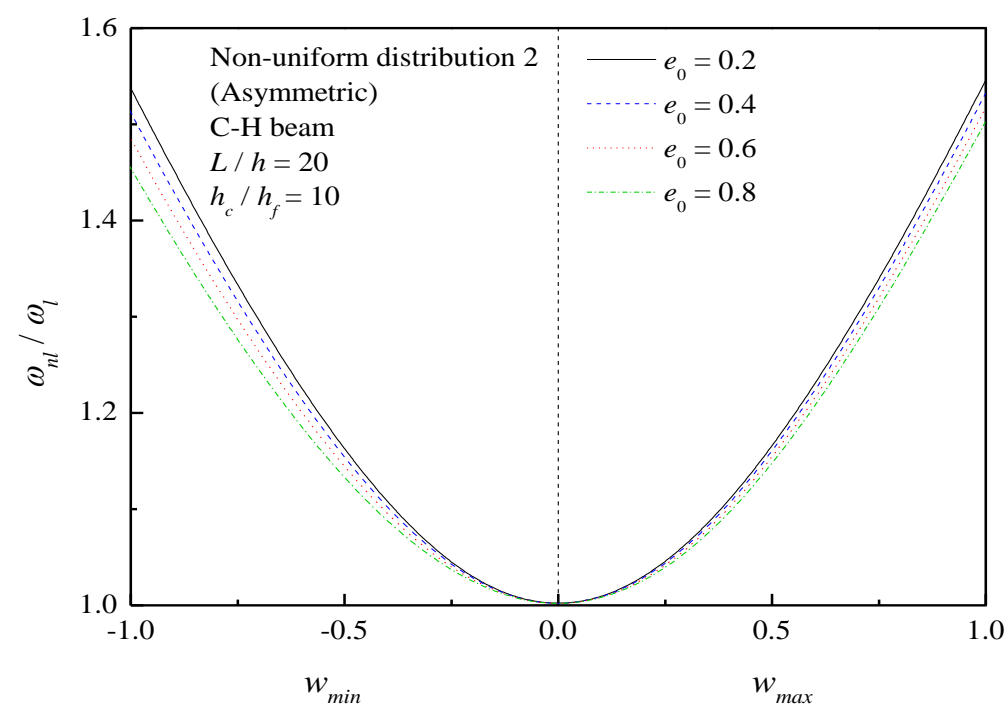

(c) $\mathrm{C}-\mathrm{H}$ beam

Fig. 4. Nonlinear frequency ratio versus vibration amplitude curves for sandwich porous beams with non-uniform porosity distribution 2 : effect of porosity coefficient.



Fig. 5. Nonlinear frequency ratio versus vibration amplitude curves for $\mathrm{H}-\mathrm{H}$ sandwich porous beams with uniform porosity distribution: effect of porosity coefficient.

\subsection{Effects of slenderness ratio}

Tables 4-6 examine the effects of slenderness ratio on the nonlinear frequency ratio of sandwich porous beams together with the dimensionless linear fundamental frequency which decreases dramatically with an increased slenderness ratio. The nonlinear frequency ratio also drops as the slenderness ratio increases, but unlike the fundamental frequency, its decrease is seen to be quite small at smaller vibration amplitudes then become slightly bigger at larger vibration amplitudes. 


\section{Table 4}

Nonlinear frequency ratio $\omega_{n l} / \omega_{l}$ of sandwich porous beams with non-uniform porosity distribution 1 : effect of slenderness ratio $\left(e_{0}=0.5, h_{c} / h_{f}=10\right)$.

\begin{tabular}{|c|c|c|c|c|c|c|}
\hline \multirow{2}{*}{$L / h$} & \multirow{2}{*}{$\omega_{l}$} & \multicolumn{5}{|l|}{$w_{\max }$} \\
\hline & & 0.2 & 0.4 & 0.6 & 0.8 & 1.0 \\
\hline \multicolumn{7}{|c|}{ H-H beam } \\
\hline 20 & 0.1458 & 1.0485 & 1.1820 & 1.3765 & 1.6093 & 1.8654 \\
\hline 30 & 0.0975 & 1.0483 & 1.1812 & 1.3749 & 1.6070 & 1.8626 \\
\hline 40 & 0.0732 & 1.0482 & 1.1809 & 1.3744 & 1.6062 & 1.8616 \\
\hline 50 & 0.0586 & 1.0482 & 1.1808 & 1.3741 & 1.6058 & 1.8611 \\
\hline \multicolumn{7}{|c|}{$C$-C beam } \\
\hline 20 & 0.3248 & 1.0120 & 1.0470 & 1.1026 & 1.1747 & 1.2610 \\
\hline 30 & 0.2193 & 1.0118 & 1.0465 & 1.1015 & 1.1732 & 1.2590 \\
\hline 40 & 0.1653 & 1.0118 & 1.0463 & 1.1012 & 1.1727 & 1.2584 \\
\hline 50 & 0.1325 & 1.0118 & 1.0462 & 1.1010 & 1.1725 & 1.2581 \\
\hline \multicolumn{7}{|c|}{ C-H beam } \\
\hline 20 & 0.2260 & 1.0242 & 1.0927 & 1.1971 & 1.3278 & 1.4768 \\
\hline 30 & 0.1518 & 1.0240 & 1.0921 & 1.1959 & 1.3269 & 1.4746 \\
\hline 40 & 0.1142 & 1.0239 & 1.0919 & 1.1956 & 1.3263 & 1.4740 \\
\hline 50 & 0.0914 & 1.0239 & 1.0918 & 1.1954 & 1.3260 & 1.4737 \\
\hline
\end{tabular}

Table 5

Nonlinear frequency ratio $\omega_{n l} / \omega_{l}$ of sandwich porous beams with non-uniform porosity distribution 2 : effect of slenderness ratio $\left(e_{0}=0.5, h_{c} / h_{f}=10\right)$.

\begin{tabular}{|c|c|c|c|c|c|c|}
\hline \multirow{2}{*}{$L / h$} & \multirow{2}{*}{$\omega_{l}$} & \multicolumn{5}{|l|}{$w_{\max }$} \\
\hline & & 0.2 & 0.4 & 0.6 & 0.8 & 1.0 \\
\hline \multicolumn{7}{|c|}{ H-H beam } \\
\hline 20 & 0.1404 & 1.0516 & 1.2022 & 1.4224 & 1.6801 & 1.9596 \\
\hline 30 & 0.0939 & 1.0513 & 1.2014 & 1.4208 & 1.6788 & 1.9560 \\
\hline 40 & 0.0705 & 1.0512 & 1.2012 & 1.4203 & 1.6780 & 1.9550 \\
\hline 50 & 0.0564 & 1.0512 & 1.2010 & 1.4203 & 1.6776 & 1.9545 \\
\hline \multicolumn{7}{|c|}{ C-C beam } \\
\hline 20 & 0.3109 & 1.0131 & 1.0512 & 1.1114 & 1.1898 & 1.2823 \\
\hline 30 & 0.2097 & 1.0130 & 1.0507 & 1.1107 & 1.1884 & 1.2804 \\
\hline 40 & 0.1579 & 1.0129 & 1.0506 & 1.1103 & 1.1879 & 1.2798 \\
\hline 50 & 0.1266 & 1.0129 & 1.0505 & 1.1102 & 1.1877 & 1.2796 \\
\hline \multicolumn{7}{|c|}{ C-H beam } \\
\hline 20 & 0.2164 & 1.0264 & 1.1023 & 1.2183 & 1.3621 & 1.5248 \\
\hline 30 & 0.1453 & 1.0262 & 1.1017 & 1.2169 & 1.3600 & 1.5221 \\
\hline 40 & 0.1092 & 1.0262 & 1.1015 & 1.2165 & 1.3595 & 1.5215 \\
\hline 50 & 0.0875 & 1.0261 & 1.1014 & 1.2163 & 1.3592 & 1.5216 \\
\hline
\end{tabular}




\section{Table 6}

Nonlinear frequency ratio $\omega_{n l} / \omega_{l}$ of sandwich porous beams with uniform porosity distribution: effect of slenderness ratio $\left(e_{0}=0.5, h_{c} / h_{f}=10\right)$.

\begin{tabular}{|c|c|c|c|c|c|c|}
\hline \multirow{2}{*}{$L / h$} & \multirow{2}{*}{$\omega_{l}$} & \multicolumn{5}{|l|}{$w_{\max }$} \\
\hline & & 0.2 & 0.4 & 0.6 & 0.8 & 1.0 \\
\hline \multicolumn{7}{|c|}{ H-H beam } \\
\hline 20 & 0.1383 & 1.0527 & 1.1965 & 1.4041 & 1.6513 & 1.9238 \\
\hline 30 & 0.0925 & 1.0524 & 1.1958 & 1.4031 & 1.6498 & 1.9196 \\
\hline 40 & 0.0694 & 1.0524 & 1.1955 & 1.4026 & 1.6490 & 1.9187 \\
\hline 50 & 0.0556 & 1.0523 & 1.1954 & 1.4023 & 1.6486 & 1.9182 \\
\hline \multicolumn{7}{|c|}{$C$-C beam } \\
\hline 20 & 0.3084 & 1.0130 & 1.0509 & 1.1106 & 1.1884 & 1.2808 \\
\hline 30 & 0.2081 & 1.0129 & 1.0504 & 1.1099 & 1.1870 & 1.2789 \\
\hline 40 & 0.1567 & 1.0128 & 1.0502 & 1.1096 & 1.1865 & 1.2782 \\
\hline 50 & 0.1256 & 1.0128 & 1.0502 & 1.1094 & 1.1863 & 1.2780 \\
\hline \multicolumn{7}{|c|}{ C-H beam } \\
\hline 20 & 0.2145 & 1.0262 & 1.1005 & 1.2130 & 1.3529 & 1.5118 \\
\hline 30 & 0.1440 & 1.0261 & 1.0997 & 1.2113 & 1.3504 & 1.5097 \\
\hline 40 & 0.1082 & 1.0260 & 1.0995 & 1.2110 & 1.3499 & 1.5078 \\
\hline 50 & 0.0867 & 1.0260 & 1.0994 & 1.2108 & 1.3496 & 1.5075 \\
\hline
\end{tabular}

\subsection{Effects of thickness ratio}

We then look into the effect of thickness ratio $h_{c} / h_{f}$. As shown in Fig. 6, an increase in the thickness ratio only results in a very small drop in nonlinear frequency ratio for sandwich beams with non-uniform porosity distribution 1. This is different from the results for beams with porosity distribution 2 and uniform distribution depicted in Figs. 7 and 8 which show that the nonlinear frequency ratio does have a fairly big increase as the thickness ratio increases. It should be mentioned that a smaller thickness ratio corresponds to a sandwich beam which is closer to a pure steel beam without internal pores with an increased beam stiffness thus higher linear and nonlinear frequencies. In this section, the total beam thickness is kept constant while both $h_{c}$ and $h_{f}$ are varied. 


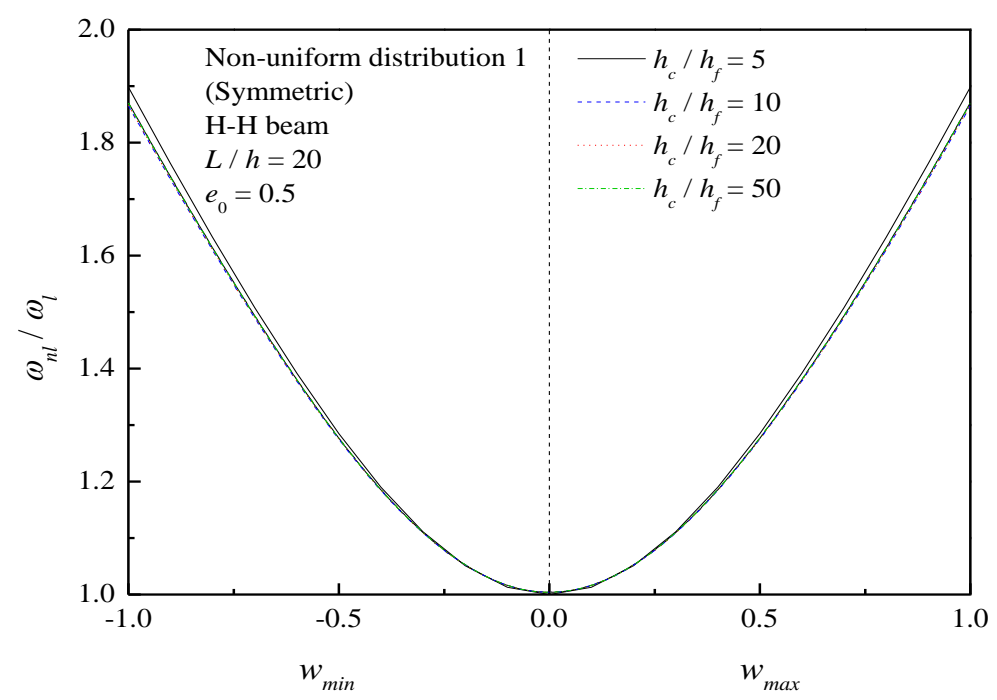

Fig. 6. Nonlinear frequency ratio versus vibration amplitude curves for $\mathrm{H}-\mathrm{H}$ sandwich porous beams with non-uniform porosity distribution 1 : effect of thickness ratio.

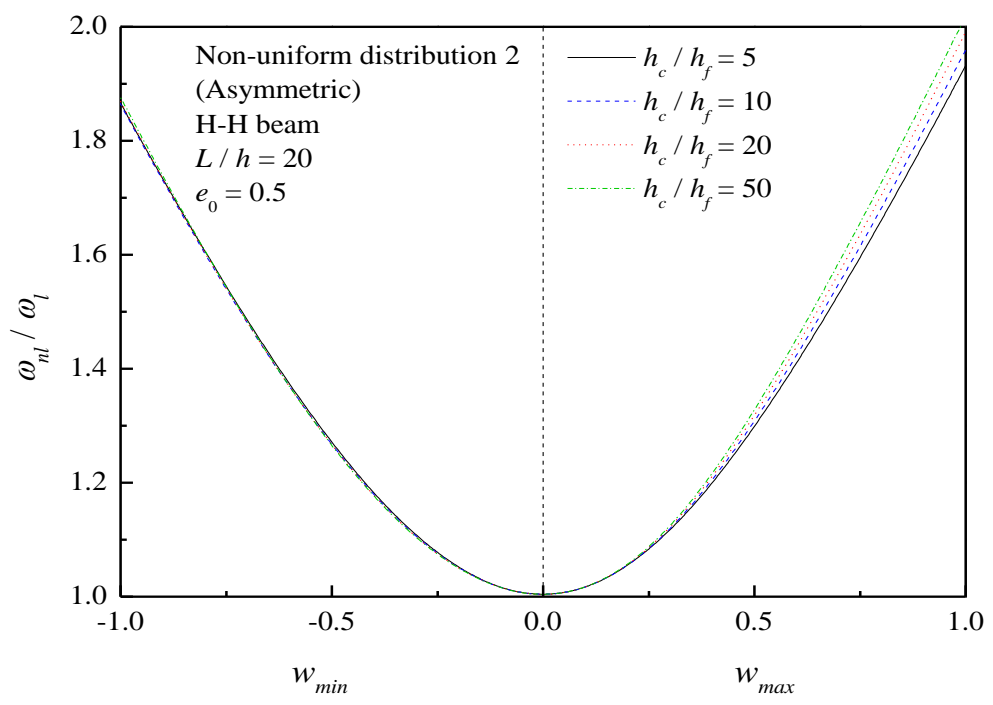

(a) $\mathrm{H}-\mathrm{H}$ beam 


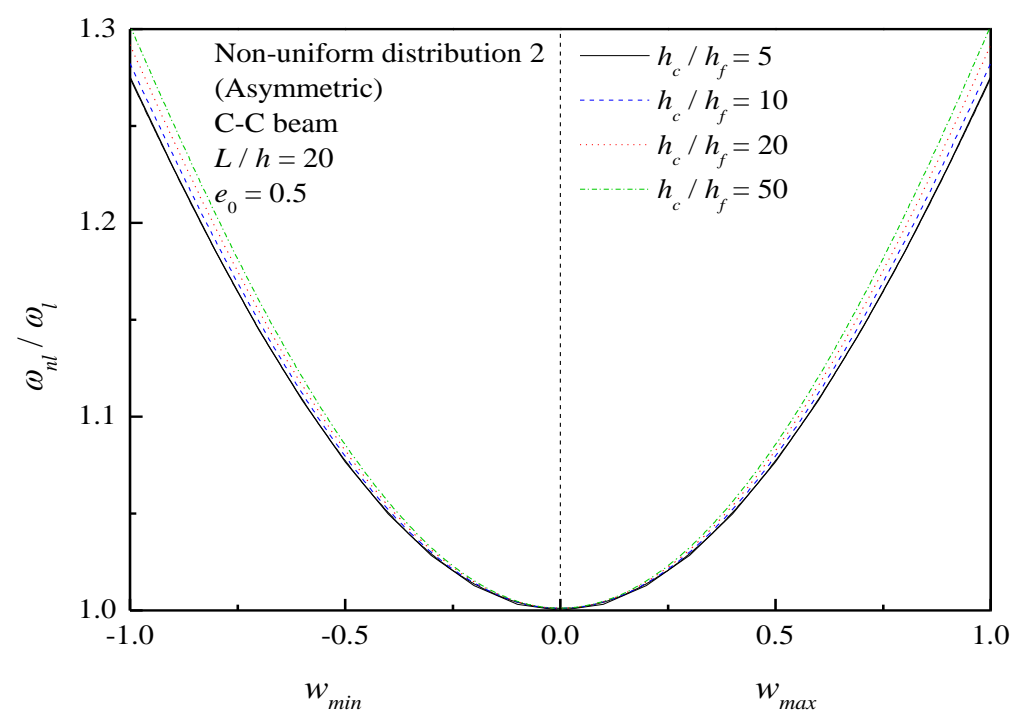

(b) C-C beam



(c) C-H beam

Fig. 7. Nonlinear frequency ratio versus vibration amplitude curves for sandwich porous beams with non-uniform porosity distribution 2 : effect of thickness ratio. 


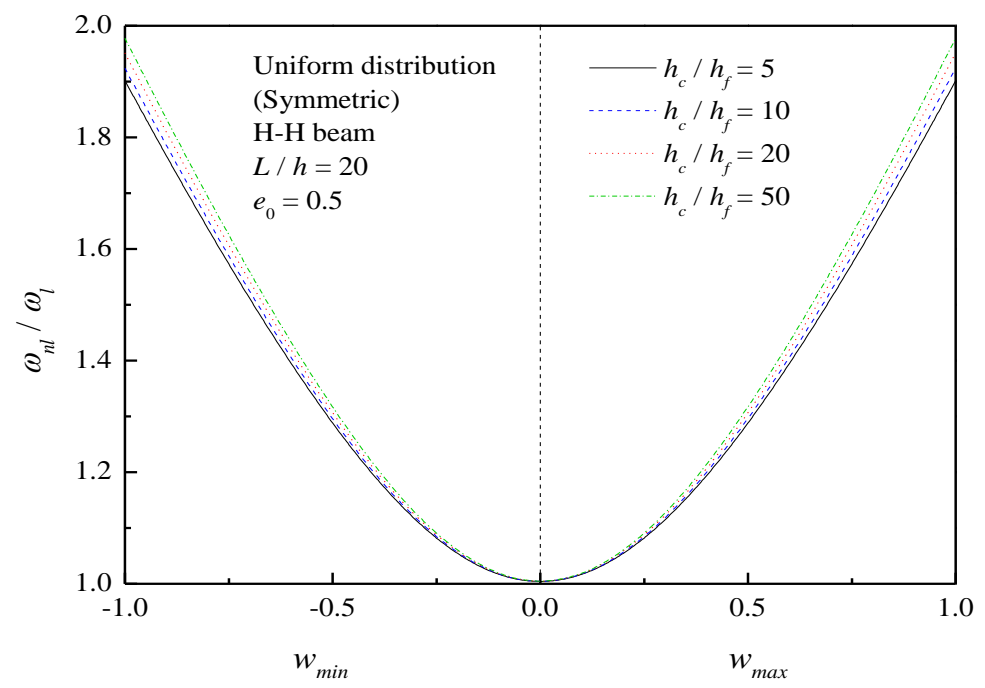

Fig. 8. Nonlinear frequency ratio versus vibration amplitude curves for $\mathrm{H}-\mathrm{H}$ sandwich porous beams with uniform porosity distribution: effect of thickness ratio.

\subsection{Comparisons between porosity distributions}

Fig. 9 compares the nonlinear vibration performance of beams with different porosity distributions and boundary conditions. Results show that non-uniform porosity distribution 1 yields the highest nonlinear frequency but the lowest nonlinear frequency ratio. It can also be seen from Tables 4-6 that the linear fundamental frequency in this case is also the highest. This indicates that compared with the other porosity distributions, non-uniform porosity distribution 1 offers the best structural stiffness for the sandwich porous beam. As can be expected, the fully clamped sandwich beam has the lowest nonlinear frequency ratio and the highest linear and nonlinear frequencies.

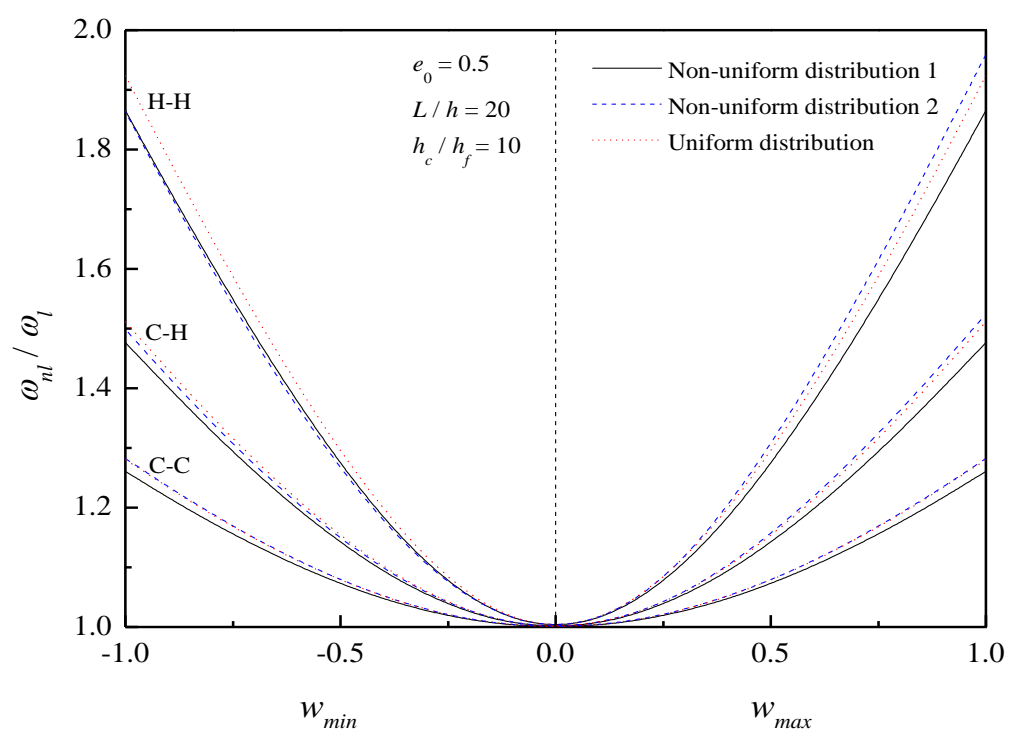

(a) Nonlinear frequency ratio versus amplitude 


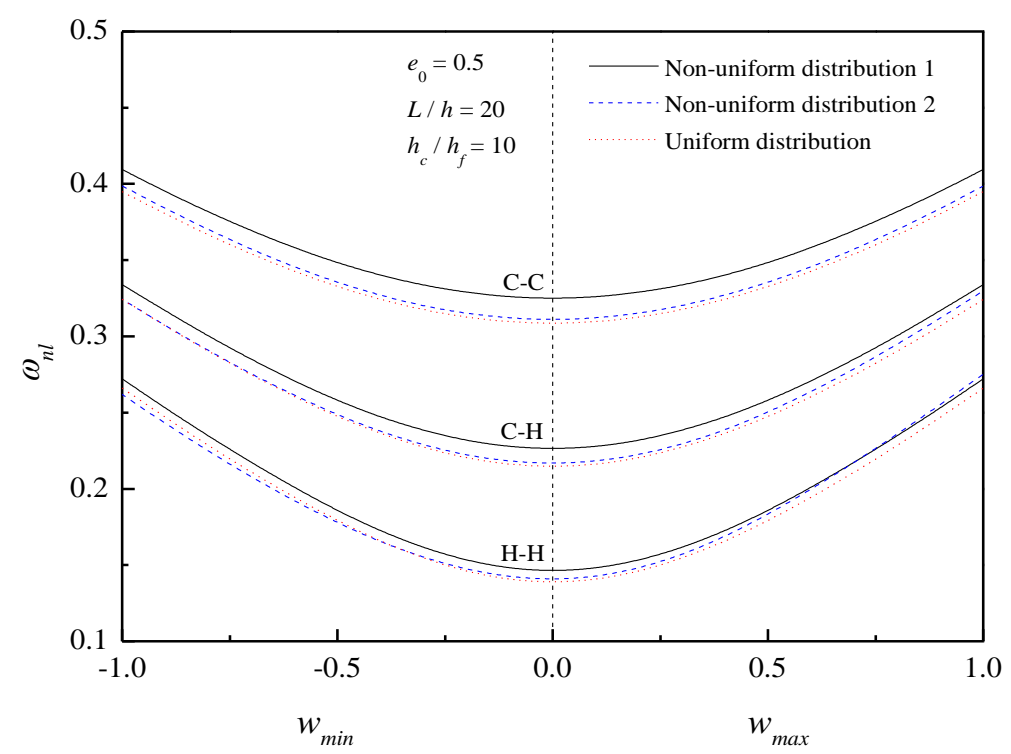

(b) Nonlinear frequency versus amplitude

Fig. 9. Comparisons of nonlinear frequency ratios and nonlinear frequencies of sandwich porous beams with different porosity distributions and boundary conditions

\section{Concluding remarks}

The nonlinear free vibration of shear deformable sandwich beam with a functionally graded porous core is studied in this paper within the framework of Timoshenko beam theory, von Kármán type geometric nonlinearity and Ritz method. It can be concluded from numerical results that

(1) An increase in the vibration amplitude leads to a larger nonlinear frequency ratio of sandwich porous beams;

(2) As the porosity coefficient increases, the nonlinear frequency ratios for beams with different porosity distributions decrease with varying amplitudes;

(3) The nonlinear frequencies of $\mathrm{H}-\mathrm{H}$ and $\mathrm{C}-\mathrm{H}$ sandwich beams with non-uniform porosity distribution 2 is dependent on the sign of vibration amplitudes;

(4) The effect of slenderness ratio is remarkable for linear fundamental frequency but relatively small for nonlinear frequency ratio;

(5) The effect of thickness ratio on the nonlinear frequency ratio is marginal for beams with non-uniform porosity distribution 1 but is more significant for beams with non-uniform porosity distribution 2 and uniform porosity distribution;

(6) Non-uniform porosity distribution 1 offers the highest beam stiffness hence the largest nonlinear frequency, indicating that an FG porous core in which internal pores are symmetrically and non-uniformly distributed can achieve the best vibration performance.

\section{Acknowledgments}


The work described in this paper was fully funded by two research grants from the Australian Research Council under Discovery Project scheme (DP130104358, DP140102132). The authors are grateful for their financial support.

\section{References}

[1] M.F. Ashby, T. Evans, N.A. Fleck, J. Hutchinson, H. Wadley, L. Gibson, Metal Foams: A Design Guide, Elsevier, 2000.

[2] L.J. Gibson, M.F. Ashby, Cellular Solids: Structure and Properties, Cambridge university press, 1997.

[3] J. Banhart, Manufacture, characterisation and application of cellular metals and metal foams, Progress in Materials Science. 46 (2001) 559-632.

[4] L.-P. Lefebvre, J. Banhart, D. Dunand, Porous metals and metallic foams: current status and recent developments, Advanced Engineering Materials. 10 (2008) 775-787.

[5] B. Smith, S. Szyniszewski, J. Hajjar, B. Schafer, S. Arwade, Steel foam for structures: A review of applications, manufacturing and material properties, Journal of Constructional Steel Research. 71 (2012) 1-10.

[6] M.F. Ashby, T. Lu, Metal foams: a survey, Science in China Series B: Chemistry. 46 (2003) 521-532.

[7] C. Zhao, Review on thermal transport in high porosity cellular metal foams with open cells, International Journal of Heat and Mass Transfer. 55 (2012) 3618-3632.

[8] N. Dukhan, Metal Foams: Fundamentals and Applications, DEStech Publications, Inc, 2013.

[9] C. Betts, Benefits of metal foams and developments in modelling techniques to assess their materials behaviour: a review, Materials Science and Technology. 28 (2012) 129-143.

[10] G. Davies, S. Zhen, Metallic foams: their production, properties and applications, Journal of Materials Science. 18 (1983) 1899-1911.

[11] Q.H. Qin, T. Wang, An analytical solution for the large deflections of a slender sandwich beam with a metallic foam core under transverse loading by a flat punch, Composite Structures. 88 (2009) 509-518.

[12] Q.H. Qin, T. Wang, Low-velocity heavy-mass impact response of slender metal foam core sandwich beam, Composite Structures. 93 (2011) 1526-1537.

[13] V. Tagarielli, V. Deshpande, N. Fleck, The dynamic response of composite sandwich beams to transverse impact, International Journal of Solids and Structures. 44 (2007) 2442-2457.

[14] H.-Y. Kim, W. Hwang, Effect of debonding on natural frequencies and frequency response functions of honeycomb sandwich beams, Composite Structures. 55 (2002) 51-62.

[15] A. Shahdin, L. Mezeix, C. Bouvet, J. Morlier, Y. Gourinat, Fabrication and mechanical testing of glass fiber entangled sandwich beams: A comparison with honeycomb and foam sandwich beams, Composite Structures. 90 (2009) 404-412.

[16] S. Yu, W. Cleghorn, Free flexural vibration analysis of symmetric honeycomb panels, Journal of Sound and Vibration. 284 (2005) 189-204.

[17] P. Jasion, K. Magnucki, Global buckling of a sandwich column with metal foam core, Journal of Sandwich Structures and Materials. (2013) 1099636213499339.

[18] V. Crupi, R. Montanini, Aluminium foam sandwiches collapse modes under static and dynamic three-point bending, International Journal of Impact Engineering. 34 (2007) 509-521.

[19] V. Tagarielli, N. Fleck, A comparison of the structural response of clamped and simply supported sandwich beams with aluminium faces and a metal foam core, Journal of Applied Mechanics. 72 (2005) 408-417.

[20] L. Jing, Z. Wang, J. Ning, L. Zhao, The dynamic response of sandwich beams with open-cell metal foam cores, Composites Part B: Engineering. 42 (2011) 1-10.

[21] H.N. Wadley, N.A. Fleck, A.G. Evans, Fabrication and structural performance of periodic cellular metal sandwich structures, Composites Science and Technology. 63 (2003) 2331-2343.

[22] T. McCormack, R. Miller, O. Kesler, L. Gibson, Failure of sandwich beams with metallic foam cores, International Journal of Solids and Structures. 38 (2001) 4901-4920. 
[23] P. Jasion, E. Magnucka-Blandzi, W. Szyc, K. Magnucki, Global and local buckling of sandwich circular and beam-rectangular plates with metal foam core, Thin-Walled Structures. 61 (2012) 154-161.

[24] U.K. Vaidya, S. Pillay, S. Bartus, C.A. Ulven, D.T. Grow, B. Mathew, Impact and post-impact vibration response of protective metal foam composite sandwich plates, Materials Science and Engineering: A. 428 (2006) 59-66.

[25] D. Radford, G. McShane, V. Deshpande, N. Fleck, The response of clamped sandwich plates with metallic foam cores to simulated blast loading, International Journal of Solids and Structures. 43 (2006) 2243-2259.

[26] A. Hanssen, Y. Girard, L. Olovsson, T. Berstad, M. Langseth, A numerical model for bird strike of aluminium foam-based sandwich panels, International Journal of Impact Engineering. 32 (2006) 1127-1144.

[27] K. Magnucki, P. Stasiewicz, Elastic buckling of a porous beam, Journal of Theoretical and Applied Mechanics. 42 (2004) 859-868.

[28] D. Chen, J. Yang, S. Kitipornchai, Elastic buckling and static bending of shear deformable functionally graded porous beam, Composite Structures. 133 (2015) 54-61.

[29] D. Chen, J. Yang, S. Kitipornchai, Free and forced vibrations of shear deformable functionally graded porous beams, International Journal of Mechanical Sciences. 108 (2016) 14-22.

[30] E. Magnucka-Blandzi, K. Magnucki, Effective design of a sandwich beam with a metal foam core, Thin-Walled Structures. 45 (2007) 432-438.

[31] E. Magnucka-Blandzi, Mathematical modelling of a rectangular sandwich plate with a metal foam core, Journal of Theoretical and Applied Mechanics. 49 (2011) 439-455.

[32] M. Grygorowicz, K. Magnucki, M. Malinowski, Elastic buckling of a sandwich beam with variable mechanical properties of the core, Thin-Walled Structures. 87 (2015) 127-132.

[33] A. Mojahedin, M. Jabbari, A. Khorshidvand, M. Eslami, Buckling analysis of functionally graded circular plates made of saturated porous materials based on higher order shear deformation theory, Thin-Walled Structures. 99 (2016) 83-90.

[34] S. Kitipornchai, J. Yang, K. Liew, Semi-analytical solution for nonlinear vibration of laminated FGM plates with geometric imperfections, International Journal of Solids and Structures. 41 (2004) 2235-2257.

[35] M. Rafiee, J. Yang, S. Kitipornchai, Large amplitude vibration of carbon nanotube reinforced functionally graded composite beams with piezoelectric layers, Composite Structures. 96 (2013) 716-725.

[36] S. Belouettar, L. Azrar, E. Daya, V. Laptev, M. Potier-Ferry, Active control of nonlinear vibration of sandwich piezoelectric beams: a simplified approach, Computers \& Structures. 86 (2008) 386-397.

[37] J. Choi, R. Lakes, Analysis of elastic modulus of conventional foams and of re-entrant foam materials with a negative Poisson's ratio, International Journal of Mechanical Sciences. 37 (1995) 51-59.

[38] S. Kitipornchai, L. Ke, J. Yang, Y. Xiang, Nonlinear vibration of edge cracked functionally graded Timoshenko beams, Journal of Sound and Vibration. 324 (2009) 962-982.

[39] H. Wu, S. Kitipornchai, J. Yang, Free Vibration and Buckling Analysis of Sandwich Beams with Functionally Graded Carbon Nanotube-Reinforced Composite Face Sheets, International Journal of Structural Stability and Dynamics. (2015) 1540011.

[40] S. Marur, G. Prathap, Non-linear beam vibration problems and simplifications in finite element models, Computational Mechanics. 35 (2005) 352-360.

[41] L.-L. Ke, J. Yang, S. Kitipornchai, Nonlinear free vibration of functionally graded carbon nanotube-reinforced composite beams, Composite Structures. 92 (2010) 676-683.

[42] L.-L. Ke, Y.-S. Wang, J. Yang, S. Kitipornchai, Nonlinear free vibration of size-dependent functionally graded microbeams, International Journal of Engineering Science. 50 (2012) 256267. 